\title{
9 INTERORGANIZATIONAL SYSTEMS ADOPTION: A Socio-Technical Perspective
}

\author{
Deborah Bunker \\ University of New South Wales \\ Sydney, Australia \\ Karlheinz Kautz \\ Copenhagen Business School \\ Frederiksburg, Denmark \\ Clayton Pyne \\ University of New South Wales \\ Sydney, Australia
}

\begin{abstract}
This paper discusses a case study of an electronic data interchange (EDI) interorganizational system (IOS) adoption project between two organizations (ProvideCo and BuildCo) highlighting that IOS adoption is not only technological in nature and orientation but that organizational factors also play their part. As a result of the case analysis and key findings, an interorganizational collaboration model (Barratt 2004) is amended to explain and highlight the effect of organizational factors on IOS adoption. The amended model includes the relationship of technology (IOS) adoption to cross-functional collaborative activities and risk, power, opportunism, and trust.
\end{abstract}

Keywords Interorganizational systems, collaboration, information systems adoption

\section{INTRODUCTION}

Interorganizational systems (IOS) exist to support and implement cooperation and strategic alliances between two or more organizations. Interorganizational collaboration in the adoption of an IOS is driven by sharing investment costs, spreading IOS risks, and

Please use the following format when citing this chapter:

Bunker, D., Kautz, K., and Pyne, C., 2008, in IFIP International Federation for Information Processing, Volume 287, Open IT-Based Innovation: Moving Towards Cooperative IT Transfer and Knowledge Diffusion, eds. León, G., Bernardos, A., Casar, J., Kautz, K., and DeGross, J. (Boston: Springer), pp. 159-175. 
accessing each organization's resources (Kumar and van Dissel 1996). The benefits espoused by companies collaborating in IOS adoption, however, are believed to inadvertently (and somewhat ironically) cause conflict between the collaborating organizations. IOS have proved difficult to implement and there has been a failure to understand with whom to collaborate and the timing of such a collaboration (Barratt 2004). Some researchers even go so far as to say that integrated supply chain benefits cannot be achieved by all firms (Sakaguchi et al. 2002). This study provides an explanation of the relationship and impact of an IOS electronic data interchange (EDI) adoption and the collaborative culture of the organizations that adopt it. An organization's collaborative culture is shown to have a significant impact on the success of IOS adoption. As the benefits of interorganizational collaboration can only be realised if the collaboration is sustained over time, it is important that the inhibitors to interorganizational collaboration are understood, so risks can be anticipated and identified early in order to guard against the possibility of conflict and adverse impact on IOS adoption.

The links between EDI, IOS, and business success are evident throughout the literature. Positive financial performance and effective supply chain arrangements are closely linked (D'Avanzo et al. 2003). Reducing cost has typically been a preeminent driver of IOS adoption and the formation of value chain relationships, but enhancing revenue is also of prime importance (D'Avanzo et al. 2003). With this renewed strategic focus on value chain relationships, there exists a significant research gap in understanding the impact that the underlying IOS adoption has on the collaborative culture that drives the success of interorganizational collaborations. Cox (1999) believes that there are serious intellectual flaws in some of the lean thinking literature, in the equity, trust, and openness views of collaboration. Cox argues that understanding strategic and operational supply chain management is dependent on understanding the existing power structures. If they do not, Cox argues, then both practitioners and academics will recommend strategies and operational practices that are inappropriate for the supply chains in which they operate.

The central argument of this paper highlights that IOS adoption is not just technological in nature and orientation, but that cultural elements of an organization also play their part. In the remainder of the paper, we assess the current state of the literature, present the modified Barratt (2004) framework, our research method, and our case organizations as well as the EDI IOS under study. We then describe and discuss our findings, further modify the Barratt framework, and finish with some conclusions.

\section{LITERATURE REVIEW}

This paper focuses on the effects of technology adoption on the cultural, coordination, and mediating factors of interorganizational collaboration, which are thought to be driven by (and drive) IOS adoption success. The background literature, therefore, is dealt with through these themes. The concept of collaborative culture is first explained, followed by the concepts of interdependency and coordination and the potential inhibiting elements of trust (distrust), power, and opportunism on IOS adoption. IOS (technology) adoption is then looked at as a strategic element for interorganizational collaborators to consider. 


\subsection{Collaborative Culture}

Collaborative culture drives the coordinating activities of joint planning and decision making, joint performance metrics and process alignment, and is the basis for collaborative success (Kumar and van Dissel 1996; Wigand and Benjamin 1995). Two key elements repeat themselves in the literature as the defining qualities of collaboration: information exchange and communication and trust, and mutuality and communication.

Akin to the supply chain, value chains require high degrees of information exchange in order to maximize coordination: process alignment, joint decision making, and joint performance metrics (Mason-Jones and Towill 1997). Without sufficient information sharing such coordination would be unattainable. IOS have a role in this information sharing as they are the vehicle for facilitating the interorganizational activities. Information sharing is about sharing knowledge and learning for collaborative activities such as joint planning, forecasting, and process alignment. Zeng and Pathak (2003) define information integration as exchanges of information and knowledge via collaborative information sharing, planning, forecasting and replenishment. Information sharing assists partners to align to share learning, rather than just knowledge appropriation (Spekman et al. 1998). Adoption of IOS create virtual value chains, where supply is no longer based on inventory, but on information (Barratt 2004; Scott 2000). There is also a need to develop broad interfaces between organizations potentially to overcome the lack of internal coordination (Barratt and Green 2001). Information sharing is facilitated by open communication and broad contact lines at organizational boundaries so as to prevent the collaboration from dissipating when certain resources withdraw from the arrangement. Information sharing and communication, therefore, together comprise an integral element of the collaborative culture required of a value chain participant in the IOS adoption process.

A minimum level of interfirm trust is indispensable for any strategic alliance to be formed and to function (Das and Teng 1998); some trust is required to initiate interorganizational collaboration (Webb 1991). Communication and proactive information exchange are both tactics to boost trust among partners (Das and Teng 1998). The building of trust requires a willingness to communicate over a range of issues (Webb 1991). Making mutual adaptations, and recognizing mutual benefits (Scott 2000), according to the partnership is an effective way to develop trust (Das and Teng 1998). Mutuality in this study is taken from Scott's (2000) definition of mutual trust: the expectation shared by participants that they will meet their commitments to one another. With mutual trust, partners will reciprocate openness and sharing of information and knowledge over time. Communication then helps to further enhance trust because it enhances interaction between partners (Leifer and Mills 1996). This demonstrates the cyclical nature of trust; that is, reciprocated trust is the basis for cooperation (Axelrod 1984; Creed and Miles 1996; McAllister 1995). A common implicit perspective from shared information and experiences and joint knowledge creation, reciprocity in a partnership, and trading personnel with the partner build effective trust (Scott 2000). The concepts of trust, mutuality, and communication are inextricably linked and collectively drive the collaborative culture of organizations in the adoption of an IOS. 


\subsection{Interorganizational Collaboration}

Interdependence creates risks that must be managed through increased coordination between firms to capture the potential productivity improvements enabled by new interorganizational relationships (Clark and Lee 2000). Interdependencies are inherent in the coordinating activities of process alignment, joint decision making and value chain, or joint performance metrics. Interorganizational collaboration can be viewed as a set of processes crossing organizational boundaries that create interdependencies, which need to be coordinated to achieve the goals of the two organizations. The interdependencies created by an interorganizational relationship constrain how the organizations can achieve the goal of the collaboration. This is known as the coordination problem and has been covered extensively by Thompson (1967) and Galbraith (1977), who explored how dependencies may be structured to maximize organizational performance.

Coordination is managing activity dependencies (Kim 2001) and is represented as process alignment, joint decision making and value chain, or joint performance metrics. Coordination often manifests itself with respect to an IOS adoption in the form of formal mechanisms that assist in the coordination of interdependent activities (Thompson 1967). Coordination, as a subset of collaboration, is more challenging than that within a single firm as it requires joint implementation of policy and process changes between independent firms (Clark and Lee 2000). Since the adoption of the IOS requires not only supply chain transformation but also organizational process change,

managing relationships among the dependent elements' [coordination] is indispensable for higher performance and lower coordination costs that are hallmarks of successful IOS adoptions....[Furthermore,] increased interdependence without increased coordination represents an unacceptable increase in risk for both partners involved in the interorganizational relationship, but expanded coordination provides important benefits in addition to enabling firms to deal with increasing levels of dependence (Clark and Lee 2000, p. 91).

Increased interdependence without the corresponding coordination becomes a barrier to the adoption of the IOS.

\subsection{Mediating Factors}

Literature across the fields of psychology, economics, sociology, and organizational sciences focus on trust in the context of both intra- and interorganizational collaboration (Huxham and Vangen 2003). Trust is a means of coping with uncertainty (Butler and Gill 1995). Trust as a concept is important in this study as trust mitigates opportunistic behavior (Huxham and Vangen 2003). Opportunism can be a significant barrier to effective IOS adoption, as it can cause suboptimal outcomes for supply chain members as they individually pursue their own optimal outcomes (Katz et al. 2003). Opportunistic behaviors manifest themselves differently, depending on the type of IOS being adopted (Clark et al. 2001). 
EDI data sharing, as an example of IOS adoption, brings with it a minimal increase in risk as EDI service providers shirk their responsibilities for information receipt and delivery (Clark et al. 2001). The possibility of a renegotiation of rates by the providers of EDI systems also exists. If we consider the connectivity of extended EDI, it may be used to send invoices and where firms are willing to share data (Clark et al. 2001). It is the extended use of EDI that is open to data poaching by suppliers as data volumes increase (Clark et al. 2001). These levels of connectivity, and the potential risks associated with them, are of primary focus as organizations adopt their EDI IOS.

As trust is seen to be the eliminator of the fear of opportunism, the negating of power differences, and thus interagency and mistrust, is also a key concept within this study (Huxham and Vangen 2003). This sees the concept of power emerge as key to understanding the factors inhibiting interorganizational collaboration and stimulating interorganizational conflict. Moreover, value chain innovation means nothing if a participant cannot leverage their power over the critical resources in the chain and appropriate the majority of value for themselves (Cox 1999). This perspective in the literature states that it is natural for a company to act opportunistically. As IOS adoption is closely related to the elements of trust and opportunism, it is also intimately related to the power relations evident within and between organizations.

Huxham and Vangen (2003) make the link between power and trust and postulate that collaborative achievements erode trust, as collaborative achievements are manifestations of power, which are barriers to building trust. Eden and Huxham (2001) and Cox (1999) claim that organizations naturally try and impose control as control is manifested through attempting to influence an organization's collaborative partnerships. Cox also argues that organizations seek to create a hierarchy of structural dominance: a situation in which there is a dominant player within a supply chain, who is able to own and control the key resources that appropriate value.

Kumar and van Dissel (1996) propose that factors that are barriers to, or facilitators of, IOS have different enablers and technologies that must be investigated by IOS researchers. A second related aim of the Kumar and van Dissel study was to instigate research on trading partner conflict cause and resolution in an e-environment.

\subsection{Strategic Elements}

Sharing of computing technology allows for more flexibility and closer organizational integration (Holland 1995). IOS adoption facilitates interorganizational activity, whether it is a continuous replenishment program for a supermarket, vendor managed inventory, or an out-sourced billing process. IOS adoption also facilitates cross functional activities (joint planning/decision making). While this is the lean "enabling" view of technology, literature consistently implies that IOS are inextricably linked to the collaborative culture of the organizations adopting them, which in turn drives the effectiveness of coordinating activities. IOS adoption has an impact on the cultural elements, which effectively drive the collaborative culture of the organization and ultimately the success of the relationship between the adopting parties.

IOS are envisaged by an organization to harness the advantages of making the transition from interorganizational competition to interorganizational cooperation (Kumar and van Dissel 1996). Despite the economic, operational, and strategic advan- 
tages, organizations are still grappling with the concept that IOS are difficult to implement (Barratt 2004). Kumar and van Dissel liken IOS to any human endeavor, where cooperation between organizations can sometimes become conflict. While much of the literature has concerned itself with traditional economic, technical, and sociopolitical risks, few researchers have examined a link between the IOS adoption and the interorganizational collaborative process.

\section{RESEARCH FRAMEWORK}

For the purposes of combining various elements of the literature and for its relevance to the topic and substance of the research, we adapted Barratt's (2004) model of interorganizational collaboration (see Figure 1). This model defines interorganizational collaboration elements and brings clarity to how the IOS adoption may affect and be affected by interorganizational collaboration. We have also drawn on the interorganizational conflict literature (power, trust and opportunism) and incorporated this into the model as elements of power; trust (distrust) and opportunism are the drivers of interorganizational conflict. We thought it pertinent, therefore, to reflect on how these elements might impact the IOS adoption and the interorganizational collaboration. Barratt's model has thus been modified to include of the relationship (arrowed) of technology (IOS) adoption to collaborative culture through power, risk, and opportunism.

Barratt argues that organizations rely too much on technology to build IOS rather than focusing on the needs of their partners and the development of trustworthy relationships. Interorganizational collaboration has been stifled recently due to the impact that the technology is having on the collaborative culture of the organization. The modified Barratt research model assumes that the collaborative culture largely drives the success of the adoption, and it is therefore vital to understand the socio-technical link between the IOS adoption and the organizational culture of the collaborating organizations.

This study seeks to utilize this model as a starting point to understand the relationship of an IOS adoption to

(1) Cultural elements of an interorganizational collaboration (shared culture, information exchange and communication, win-win approach, and mutuality)

(2) Coordination elements of an interorganizational collaboration (cross functional activities, joint decision making/planning, joint value chain metrics, process alignment)

(3) Mediating factors within an interorganizational collaboration (power, risk, opportunism and trust and commitment)

\section{THE RESEARCH METHOD}

A case study approach was used to examine the recent adoption of an EDI IOS, based on the mature standards of EDI, to facilitate invoicing for BuildCo. BuildCo outsourced this business process to ProvideCo, and it is the interorganizational collaboration 


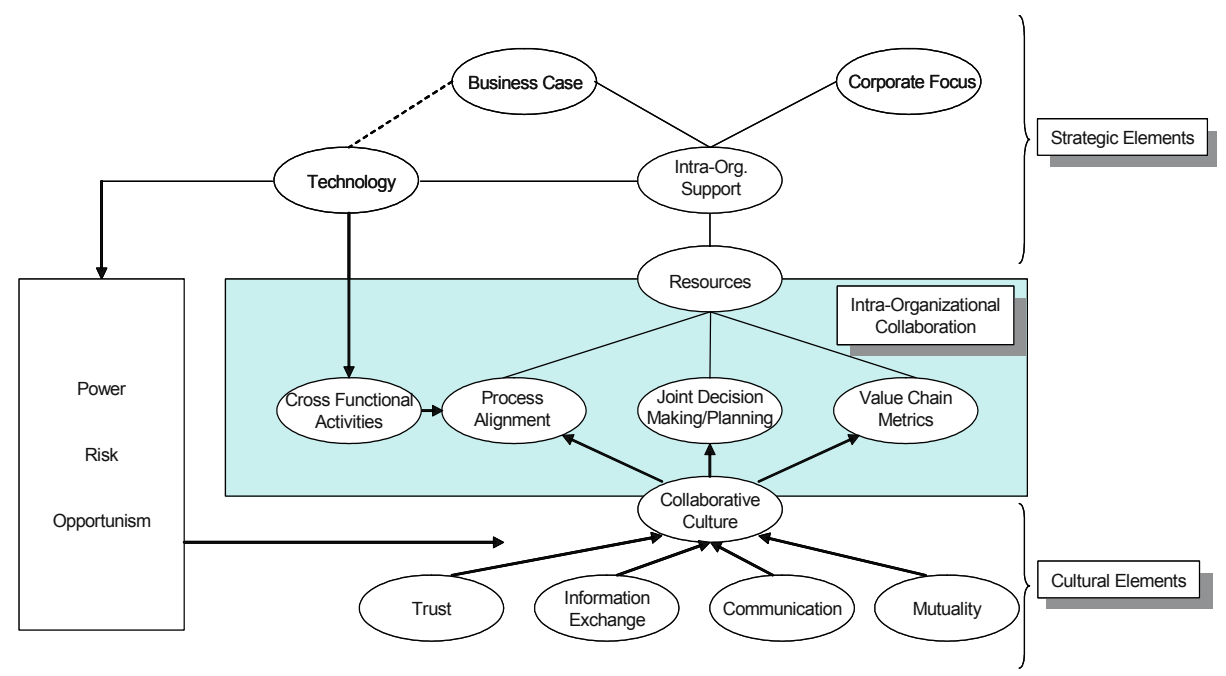

Figure 1. The Research Model for the Study: Interorganizational Collaboration (Modification of Figure 5, "The "Cultural' Elements of Supply Chain Collaboration" in Mark Barratt, "Understanding the Meaning of Collaboration in the Supply Chain," Supply Chain Management: An International Journal (9:1), 2004, p. 36. Republished with permission from Emerald Group Publishing.)

required for the adoption of this IOS between BuildCo and ProvideCo that concerns this study. The data analysis in this study includes an assessment of the cultural and coordination elements and mediating factors of the organization and how these contribute to the effectiveness of the interorganizational collaboration and the subsequent IOS adoption.

The research approach was "bricoleur-like," where a variety of sources were drawn upon pragmatically. This approach specifies that researchers use an assortment of techniques in an inventive manner to accomplish the research aims (Neuman 2003). The field method used accommodated multiple research techniques to gain knowledge (Schatzman and Anselm 1973).

Semi-structured in-depth one-on-one interviews with one key informant in BuildCo and one key informant in SupplyCo served as an effective way to extract the underlying feelings and emotions toward the interorganizational collaboration. A decision was made to sacrifice the breadth offered by possible multiple informants within ProvideCo and BuildCo for the depth and richness offered by an extensive interview with one key informant from each organization, who were both in a direct relationship with one another throughout the IOS adoption process.

The two informants functioned as IT managers for the EDI IOS adoption project, and were both the key contact for the project for their respective organization. They also operated as IT consultants directly involved with the system adoption through their work in developing and implementing the system and the new processes required between the value chain participants. Further to this, both respondents had knowledge of the wider interorganizational relationships between ProvideCo and BuildCo. 
These detailed interviews were particularly relevant for understanding the collaborative process between ProvideCo and BuildCo, allowing the researchers to probe the difficulties, problems, and conflict involved. At times the interviews were directive, to focus on certain concepts the literature had revealed and to probe vague responses or fleeting references and utterances of the interviewees. Other stages of the interview were nondirective, allowing the respondent to fully explain issues as they felt compelled. This approach to interviewing was used to seek out special insights into the collaborative process, always focusing on emergent issues, themes, and motifs that related to the IOS adoption. These interviews also explored the impact that cultural elements have on interorganizational collaboration as effected by the IOS adoption, and also allowed respondents to speak openly and freely about such concepts as trust, power, and opportunism.

Scenario analysis was also used in interviews when a question was too politically sensitive to ask directly (mainly used when encountering questions of trust, power, or opportunism). This approach proved to be very useful for identifying socio-political behaviors and the potential for conflict between the parties.

Documentary analysis (of documents obtained from BuildCo and SupplyCo) was the primary source of data for this study and was informed by the insights gained from the two interviewees. The documents allowed the researchers to fully understand the technological architecture of the EDI IOS being adopted before interviewing the key informants, thus allowing for socio-political issues to be knowledgeably probed in the interviews. The documents also complemented interviews by allowing claims made by the respondents to be compared to the meanings in the documents. In this way, documentary artifacts offered a means of triangulating the data by offering another perspective on the EDI IOS adoption. Artefacts included functional specifications from BuildCo, ProvideCo, and third party value chain participants, e-mail correspondence, meeting minutes, the complete set of ProvideCo testing documentation, and the complete set of documents directly used by ProvideCo in its collaboration with the BuildCo Timber division. Documentation also allowed for the effective understanding of the EDI architecture and implementation between ProvideCo and BuildCo and their interorganizational collaboration over time.

This data was indexed, classified, and summarized (Neuman 2003), with the primary aim of reducing the data to a perceived factual base (Jick 1979). The data analysis utilized a thematic approach where interviews, scenarios, and documents were coded around the themes elaborated within the literature and the modified Barratt (2004) model.

The case study was conducted over six months and required frequent consultations with BuildCo and ProvideCo, where a researcher was often on site full time for some weeks. This case is more innovative than most in the IOS adoption literature as it seeks out both sides of IOS adoption and interorganizational collaboration, simultaneously seeking to understand collaboration as a holistic subject comprising of many interrelationships through culture alignment and technology use (Klein and Myers 1999). The literature claims that there has been much conflict in IOS adoption in practice and that the relevance of recent literature has been limited due to the fact that academics are not truly becoming immersed in the collaborative processes of adoption, and are therefore not realizing the power structures and struggles for value appropriation. This approach also allowed for the link between the technology adoption and elements within the Barratt model to be fully explored. 


\section{CASE BACKGROUND}

This section includes background about ProvideCo and BuildCo, indicating where the informants were positioned within their respective organizations, as well as background information on the EDI IOS adoption.

\subsection{ProvideCo}

ProvideCo claims to be Australia's leading provider of quality information and image management services, helping leading businesses and major governing bodies to communicate effectively with their customers. It has 900 employees in branches in Sydney, Melbourne, Brisbane, Adelaide, Canberra, and Perth who provide services including consultancy in services integration, solutions development, and process reengineering; data formatting and management; document design and creation; document collation and distribution; response capture and conversion management; image storage and retrieval in billing, Internet billing, database management, ballots, elections, public floats, privatization, demutualization, and the digitization, storage, and retrieval of essential business information. Their clients include telecos, government agencies, financial services organizations, and media companies.

Their group IT structure (departments) consists of NSW Consulting Team, Victorian Consulting Team, Research and Development (R\&D), and National IT. The NSW Consulting Team manager has direct reporting responsibility to the Group IT/R\&D manager, who reports to the board and managing director. There is a participative management style evident in ProvideCo, where cross-functional teams are often assembled from across Group IT/R\&D due to the skill sets and expertise required by the project.

The informant, $C C$, is an IT consultant within the NSW Consulting Team (Group IT/R\&D). CC works directly with the personnel within the organization as required without restriction from management. Consultants within the NSW consulting team meet with the NSW Consulting Team manager on an ad hoc basis as required. Depending on demand and market conditions, each IT consultant may have sole responsibility for as many as 10 projects simultaneously.

\subsection{BuildCo}

BuildCo describes itself as a large building and construction materials company headquartered in Australia, with leading local and international market positions. It employs 13,000 people at many sites in Australia, the United States, and Asia. Its organizational divisions include Australian Construction Materials; Cement, Clay \& Concrete Products; Plasterboard; Timber; and BuildCo USA. BuildCo has around A $\$ 4$ billion sales per annum and its products and services include construction materials; cement, clay and concrete products; plasterboard; timber; and BuildCo (USA), which are the direct product outputs from its divisional structure. BuildCo's clients include construction companies, retail outlets, and subcontractors.

BuildCo has been a longstanding institution in Australia, a large respected company that is closely intertwined with the evolution of the Australian building and construction 
industry since the 1940s. It has a long and successful history of mergers and acquisitions, which steadily built the business in a diversity of industries until February 2000, when a de-merger resulted in the listing of BuildCo separately from another spin-off company. The Timber Division of BuildCo is a national business employing around 600 people in hardwood, plywood, and softwood operations predominantly on the east coast of Australia, which manufactures and distributes a broad range of products for domestic and export markets. The group IT structure (departments) comprise of decentralized IT units in each part of the business.

Informant MB is an IT consultant within the Timber Division. As can be seen from the description of BuildCo's history and the businesses within the business unit, IT is not a core competency of BuildCo. IT within BuildCo is seen as a facilitator that provides opportunity to streamline business processes and improve the efficiency of noncore functions within the company. MB confirmed this in the case, saying the "next move [for Timber] is to push all transactions through ProvideCo." The lack of IT expertise of BuildCo Timber is another dominant factor within the case. When asked whether there is any coordination of IT across the business units, MB responded, "Each business system manager from each division meets on a bi-monthly basis." Despite these meetings, there is no evidence in the case that these meetings are having any positive impact on the collaboration with ProvideCo, as BuildCo was always uncoordinated in their approach to the project from an aggregate perspective.

\subsection{The IOS Collaboration: EDI Adoption}

Clark et al. (2001) state that as an example of IOS collaboration EDI increased from $10 \%$ in 1990 to $30 \%$ in the late 1990 s. The implementation of an EDI IOS serves, therefore, as a valid and applicable example to relate such socio-political elements as shared culture, power and opportunism in an IOS adoption. Our focus in this paper is on the interorganizational collaboration that takes place between ProvideCo and the BuildCo Timber Division. This necessarily crosses organizational boundaries in the analysis of such issues as trust and opportunistic behavior, as the collaboration between BuildCo and ProvideCo is mediated by the relationships held between them. The case background of these companies, outlined above, serves to provide for the wider context of understanding of their collaboration in the IOS adoption and its use.

EDI is an evolving technology, which has been impacted (by varying degrees in different industries) by the rapid growth of the Internet. In recent years, there has been a divergence from traditional EDI, where transmission is facilitated by private/valueadded networks, to the standardized TCP/IP protocol offered by Internet EDI (Kumar and Crook 1999).

Throughout the case interviews, the respondents constantly discussed the segregation of the BuildCo business into autonomous product divisions as a point of conflict between ProvideCo and BuildCo. The collaboration between ProvideCo and BuildCo was at times stifled due to the lack of coordination between the BuildCo's business units. This was because the BuildCo Timber Division, which is the division of focus here, was not the only business unit within BuildCo implementing the EDI IOS project. The identical requirement was placed on other BuildCo divisions by their head office. The project was being delivered by ProvideCo to the Cement Division, which occurred after delivery to 
the Timber Division. At the same time Timber was being developed, requirements gathering and analysis was also being performed for the Plasterboard Division of BuildCo.

Frustrations and annoyances arose between ProvideCo and BuildCo as ProvideCo was having to communicate the identical requirements to multiple business units within BuildCo as each BuildCo division had completely separate IT systems. This caused ProvideCo to be constantly repeating requirements that were identical across the different units. BuildCo was not interested in coordinating among the divisions in order to simplify the implementation. The BuildCo Timber business manager explains that "synergies within one division cannot be abstracted across BuildCo, which adds to the complexity of implementation. ProvideCo did not understand this issue, but by the same token BuildCo was not upfront in explaining the complexity of its divisions." This was a significant source of frustration for ProvideCo. The segregated structure of the BuildCo business units and their absolute independence of each other led to opportunistic behavior and other conflicts that damaged the relationship. Although the structure of the BuildCo business is contextual to the Timber Division of focus, its impact on the collaboration is critical to understanding the nature of the collaboration in this case study.

The Timber \& Hardware Exchange (T\&HE) is a business-to-business eCommerce system that provides business document exchange using the Internet and is a service offered by a third party (Pacific Commerce) through an exchange software program and infrastructure. The T\&HE is responsible for validating the hardware industry working group standards for the transmission of EDI in the Edifact format, as well as for transmission of the data once received from ProvideCo (i.e., an industry supplier/wholesaler or service provider) to the receiver CustomerCo (an industry customer). The T\&HE is the primary point of validation in the process before the data is forwarded from BuildCo through ProvideCo to the CompanyCo head office for payment (see Figure 2). The T\&HE is the IOS being adopted by ProvideCo and BuildCo and the focus of their interorganizational collaboration.

\section{CASE STUDY FINDINGS}

A number of key findings relating to the research questions became evident as the story of the IOS adoption and the associated interorganizational collaboration between BuildCo and ProvideCo emerged from the interview, scenario, and documentary data.

\section{Research Question 1: What is the relationship of IOS adoption to cultural elements of an interorganizational collaboration (shared culture, information exchange and communication, win-win approach, and mutuality)?}

Collaboration in each phase of the IOS adoption process differs significantly. Effective collaboration at different phases within IOS adoption seemed to require different cultural elements in different proportions. Early project collaboration required more of a shared culture and win-win approach in order to overcome the major obstacles of "conflicting requirements" and negate the need to "fly by the seat of our pants" (BuildCo Timber). Hence, conflicting requirements were constantly mentioned when respondents 


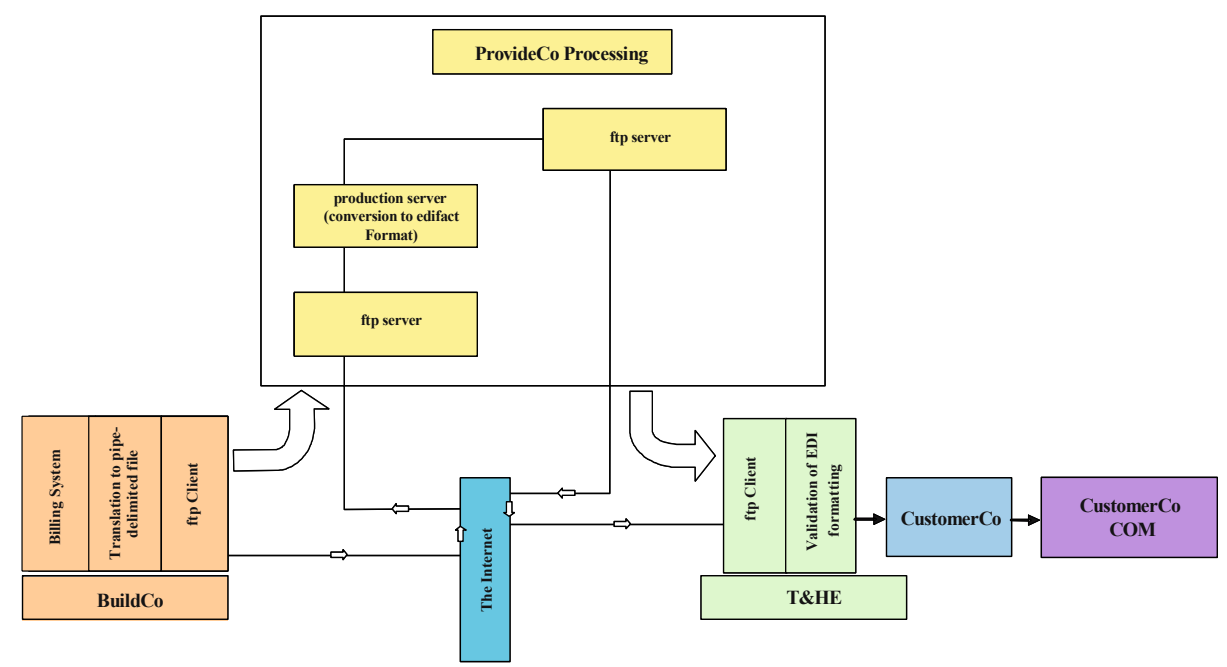

Figure 2. T\&HE Process Flows

referred to the difficulty of the early project phase collaboration. The only way this was overcome was by "making the effort to get together (face to face) and include other parties to iron out requirements." This revealed that, in the early stages of collaboration in IOS adoption such as requirements gathering and analysis and design, the collaborative elements required for success are very different from those needed for development, testing, implementation, and production. In the early project phases, the parties had to adopt a win-win approach through proactive behavior and share a culture to overcome conflicting requirements. This further substantiates the link in the model between the collaborative culture and coordination by sharing a mutual win-win perspective on understanding conflicting and slipping requirements. BuildCo and ProvideCo were both exhibiting a collaborative culture to achieve a higher level of coordination. Such interaction resulted in a degree of trust developing between the stakeholders: "We can trust ProvideCo in dealing with the other party transparently and then filtering back requirements and responses [of other stakeholders] to BuildCo." This contrasts directly with what made the collaboration successful through the development, implementation, and production stages of the project. Information exchange and communication was the predominant cultural element that contributed to the success of these phases of the project. During implementation, communication was occurring at least three or four times per week between both IT consultants MB and CC, although in production, daily operational issues were handled by other people at ProvideCo. BuildCo confirmed this high degree of interlock between the companies throughout the development, implementation, testing and production phases confirming that there is "daily e-mail communication to a number of people other than CC." Although unintended, the insight that interorganizational collaboration may be markedly different over different phases of the IOS adoption is an interesting one. 
Collaboration over the IOS adoption differed greatly from each cultural perspective. From the perspective of the two respondents, and also as evident in the supporting documentation, a win-win approach and shared culture was vital for strategic imperatives like project initiation and early stage project analysis and design, whereas information exchange and communication were more related to overcoming daily production issues in the live project environment. With respect to the cultural elements explored in this study, it can be said that operational collaboration and strategic collaboration are distinct, as posited by Cox (1999). For these two organizations, it was very different to collaborate over issues such as missing fields in pipe-delimited files than over which projects should be given the "green-light" for development in a value chain.

\section{Research Question 2: What is the relationship of IOS adoption to coordi- nation elements of an interorganizational collaboration (cross functional activities, joint decision making/planning, joint value chain metrics, process alignment)?}

IT planning must be fully integrated with business planning (intra-organizational coordination) to maximiz interorganizational coordination. This IOS adoption project plays a more reactive and facilitating role in BuildCo. Strategically, BuildCo and ProvideCo were conducting business planning, but this did not include the divisional BuildCo IT managers. The disjointedness between strategic business planning and IT planning posed many problems for the interorganizational collaboration. ProvideCo quite often found itself dealing with contradicting imperatives from different BuildCo business units while trying to satisfy the strategic planning it had conducted with BuildCo at a strategic level. The business units had no participation in, or knowledge of, this level of planning. BuildCo would impose strategic level plans on the IT managers. Both organizations were heavily coupled with respect to operational planning and decision making. The levels of planning occurring in the case and the lack of clarity around some coordination issues further supports the notion that fully integrated IT and business planning are essential for IOS adoption.

Joint performance metrics are useful as a tool to mitigate risk and maximize coordination. The lack of clarity around the issue of joint performance metrics in this value chain has led to this key finding. The complexity around joint metrics indicated a convoluted approach by BuildCo, where the Timber Division was not using all of the available information that it actually had at its disposal for monitoring performance effectively. The lack of clarity around performance metrics detracted from the coordination attainable between the value chain parties. Joint value chain metrics, utilized fully, may help identify problems more expediently, allowing for better solutions to be reached in a shorter time frame. This also cultivates a more competitive value chain with decreased overall throughput times leading to more efficient business processes. Therefore, joint decision making, joint planning, and joint value chain metrics are all vital to effective collaboration. These elements allow organizations to coordinate more effectively both at an operational level and at a strategic level.

\section{Research Question 3: What is the relationship of IOS adoption to mediating factors within an interorganizational collaboration (power, risk, opportunism and trust, and commitment)?}


Risk perception may inhibit collaborative behavior (power, trust, distrust, and opportunism). The IOS adoption does bring a direct level of risk with it. Risk is aggregated in the model as potential harm to culture through the elements of power, opportunism, and distrust. The level of risk, therefore, is reflected by the possibility that power, opportunism, and distrust will impact cultural elements in a negative fashion, ultimately leading to loose binding behavior caused by a lack of a collaborative culture. The risk of this occurring, to some extent, directly comes from the technology adopted for the interorganizational collaboration (or the perceived "riskiness" of the technology).

Risk is related to technology adoption. In the case, this is evidenced by the fact that BuildCo assumed the majority of risk for the end-to-end process, as a point of failure would prevent them from billing CustomerCo. Here, the risk of not billing relates to the process flows created by the sequentially dependent nature of the EDI technology. Clark et al. (2001) posit that these new processes (increased data sharing through technology) and new policies (operational integration) arising from the implementation cause a very large increase in risk. This is consistent with issues express by informants in this study.

Trust, power, and opportunism are affected by and come from collaboration. Elements like shared culture, win-win approach, and mutuality are important for strategic collaboration. ProvideCo and BuildCo lacked strength in trust, power, and opportunism, but were very adept at information exchange and communication. This aligned with ProvideCo and BuildCo collaborating inefficiently at a strategic level, but effectively at an operational level. These elements (shared culture, win-win approach, mutuality, information exchange, and communication), collectively constitute the collaborative culture of an organization, and are embedded to a greater or lesser degree within the organization's culture independent of the current collaboration. Conversely, the concepts of power, opportunism, and trust can come from experience of the current collaboration (e.g., the issue of BuildCo's corporate structure and its direct effect on ProvideCo's relationship with them).

Trust, power, and opportunism are affected by and come from cross functional activities. Trust can be grouped with the concepts of power and opportunism as they are all affected by and come from the current interorganizational collaboration between the companies. For example, mediation of the cross-functional activities (cultural elements) are affected by the fact that sensitive information was obtained by the BuildCo Plasterboard Division on the Timber EDI IOS adoption. This decreased the trust ProvideCo had in BuildCo, making them increasingly wary of BuildCo. This lack of trust, therefore, mediated the cultural elements, which saw a marked decrease in the win-win approach, level of shared culture and volume of information exchange that ProvideCo would adopt in future dealings with the Plasterboard Division. In this instance, the lack of trust had a negative impact on the shared culture, the win-win stance of the players, and also decreased the amount of information exchange and communication. Furthermore, the opportunistic behavior shown by Plasterboard also affected the overall interorganizational relationships and power balances and was reflected in the idiosyncratic trust ProvideCo had in BuildCo, namely the trust $\mathrm{CC}$ had in $\mathrm{MB}$. Beyond this personal relationship, there was a significant level of distrust and lack of confidence between the companies. 


\section{CONCLUSION}

As a result of the case study findings, the Barratt model has been amended to indicate that cultural elements are intrinsic to interorganizational collaboration while mediating/inhibiting elements are indirectly impacted by the technology adoption and from the repeated interorganizational collaboration (through cross functional activities) Risk has also been indirectly related to IOS adoption. As can be seen in the modified model (see Figure 3), the cross functional activities, through repeated interaction, directly give rise to the concepts of power, opportunism, trust, and, therefore, risk. Collaborative cultural elements have been shown by the case study to be antecedent to any interorganizational collaboration and dependent on such intra-organizational factors as internal business structure, management vision, and the beliefs promoted throughout the organization. ProvideCo's mantra of flexibility and fitting the customer's requirements at all costs are examples of how the elements of a collaborative culture grow organically from within an organization and precede interorganizational collaboration. In aiming to conduct business flexibly, ProvideCo exhibited an inherent need to attain a shared culture, exchange information frequently, and communicate effectively. BuildCo's data also highlights examples of the impact of a deficient internal business structure on interorganizational collaboration. The BuildCo structure had a negative impact on the cultural elements of both organizations, which revealed the mediating/inhibiting factors of trust, risk, power, and opportunism. This study has allowed for a more comprehensive view of interorganizational collaboration to be reached from modifying an existing model (Barratt 2004).

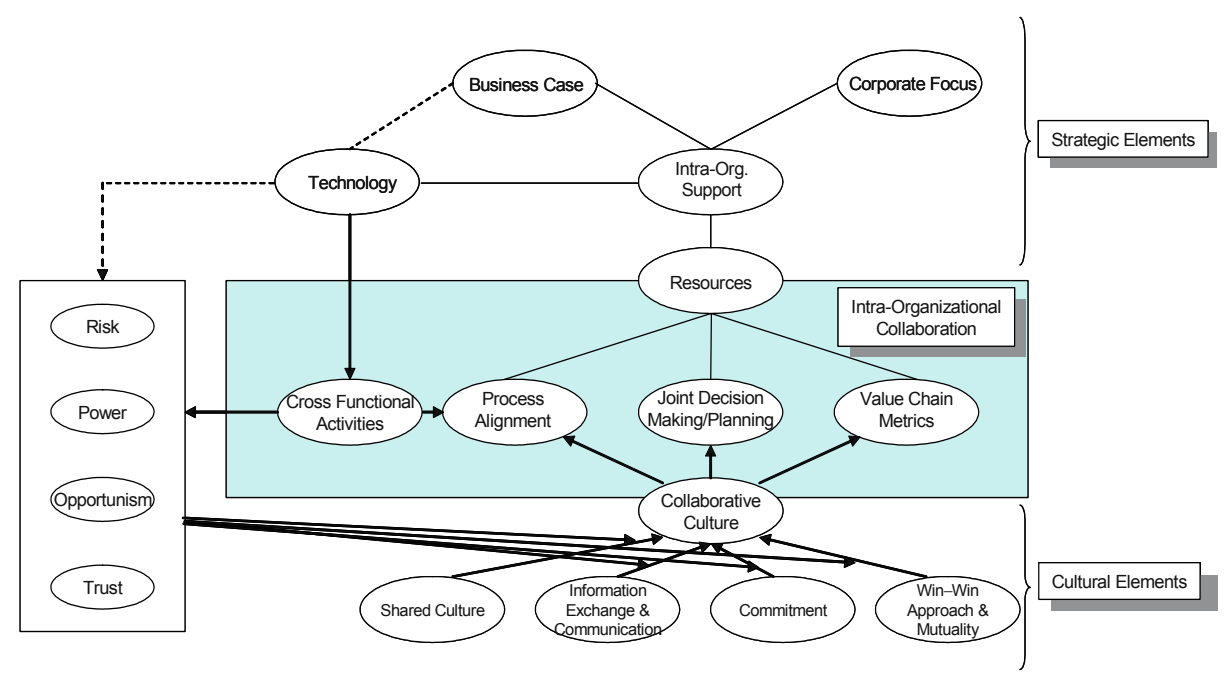

Figure 3. The Amended Research Model: ProvideCo and BuildCo (modification of Figure 5, "The 'Cultural' Elements of Supply Chain Collaboration" in Mark Barratt, "Understanding the Meaning of Collaboration in the Supply Chain," Supply Chain Management: An International Journal (9:1), 2004, p. 36) 
The amended model (see Figure 3) also indicates that dealing with the concepts of trust, power, and opportunism, which come from cross-functional activities, is of vital importance to the effectiveness of an organization's collaborative culture and the interorganizational collaboration flowing from it. It is with the acknowledgment and development of such concepts as power, opportunism, and trust (distrust) that managers will fully harness the potential of their IOS adoption and interorganizational or value chain relationships.

\section{References}

Axelrod, R. 1984. The Evolution of Cooperation, New York: Basic Books.

Barratt, M. 2004. "Understanding the Meaning of Collaboration in the Supply Chain," Supply Chain Management: An International Journal (9:1), pp. 30-42.

Barratt, M. A., and Green, M. 2001. "The Cultural Shift: The Need for a Collaborative Culture," in Proceedings of the 2001 Supply Chain Knowledge Conference, Cranfield School of Management, November.

Butler, R., and Gill, J. 1995. "Learning and Knowledge in Joint Ventures: The Importance of Trust," paper presentation, British Academy of Management Annual Conference, Sheffield.

Clark, T. H., Croson, D. C., and Schiano, W. T. 2001. "A Hierarchical Model of Supply-Chain Integration: Information Sharing and Operational Independence in the US Grocery Channel," Information Technology and Management (2), pp. 261-288.

Clark, T. H., and Lee, H.G. 2000. "Performance, Interdependence and Coordination in Businessto-Business Electronic Commerce and Supply Chain Management," Information Technology and Management (1), pp. 85-105.

Creed, W., and Miles, R. 1996. "Trust in Organizations: A Conceptual Framework Linking Organizational Forms, Managerial Philosophies, and the Opportunity Costs of Control," in Trust in Organizations: Frontiers of Theory and Research, R. M. Kramer and T. R. Tyler (eds.), Thousand Oaks, CA: Sage Publications, pp. 16-38.

Cox, A. 1999. "Power, Value and Supply Chain Management," Supply Chain Management: An International Journal (4:4), pp. 167-175.

Das, T., and Teng, B. 1998. "Between Trust and Control: Developing Confidence in Partner Cooperation in Alliances," Academy of Management Review (23:3), pp. 491-512.

D’Avanzo, R. D., Lewinski, H. V., and Van Wassenhove, L. N. 2003. "The Link Between Supply Chain and Financial Performance," Supply Chain Management Review (7:6), pp. 40-47.

Eden, C., and Huxham, C. 2001. "The Megotiation of Purpose in Multi-Organizational Collaborative Groups," Journal of Management Studies (38:3), pp. 373-391.

Galbraith, J. 1977. Organization Design, Reading, MA: Addison-Wesley.

Holland, C. P. 1995. "Cooperative Supply Chain Management: The Impact of Interorganizational Information Systems,” Journal of Strategic Information Systems (4:2), pp. 117-133.

Huxham, C., and Vangen, S. 2000. "Ambiguity, Complexity and Dynamics in the Membership of Collaboration," Human Relations (53:6), pp. 771-806.

Jick, T. D. 1979. "Mixing Qualitative and Quantitative Methods: Triangulation in Accumulation," Administrative Science Quarterly (24), pp. 602-611.

Katz, J. P., Pagell, M. D., and Bloodgood, J. M. 2003. "Strategies of Supply Communities," Supply Chain Management: An International Journal (8:4), pp. 291-302.

Kim, H. W. 2001. "Modeling Inter- and Intra-Organizational Coordination in Electronic Commerce Deployments," Information Technology and Management (2), pp. 335-354.

Klein, H. K., and Myers, M. D. 1999. "A Set of Principles for Conducting and Evaluating Interpretive Field Studies in Information Systems," MIS Quarterly (23:1), pp. 67-88. 
Kumar, R. L., and Crook, C. W. 1999. "A Multi-Disciplinary Framework for the Management of Interorganizational Systems," The DATA BASE for Advances in Information Systems (30:1), pp. 22-37.

Kumar, K., and van Dissel, H. G. 1996. 'Sustainable Collaboration: Managing Conflict and Cooperation in Interorganizational Systems,” MIS Quarterly (20:3), pp. 279-300.

Leifer, R., and Mills, P. 1996. "An Information Processing Approach for Deciding upon Control Strategies and Reducing Control Loss in Emerging Organizations," Journal of Management (22), pp. 113-137.

Mason-Jones, R., and Towill, D. R. 1997. "Information Enrichment: Designing the Supply Chain for Competitive Advantage," Supply Chain Management (2:4), pp. 137-148.

McAllister, D. 1995. "Affect- and Cognition-Based Trust as Foundations for Interpersonal Cooperation in Organizations," Academy of Management Journal (38:1), pp. 24-59.

Neuman, W. L. 2003. Social Research Methods Qualitative and Quantitative Approaches $\left(5^{\text {th }}\right.$ ed.), Boston: Allyn and Bacon.

Sakugachi, T., Nicovich, S. G., and Dibrell, C. C. 2002. "Development of an Integrated Supply Chain Model," in Proceedings of the $8^{\text {th }}$ Americas Conference on Information Systems, R. Ramsower and J. Windsor (eds.), Dallas, TX, August 9-11, pp. 2350-2351.

Schatzman, L., and Anselm, L. 1973. Field Research: Strategies for a Natural Sociology, Englewood Cliffs, NJ: Prentice-Hall.

Scott, J. E. 2000. "Facilitating Interorganizational Learning with Information Technology," Journal of Management Information Systems (17:2), pp. 81-113.

Spekman, R. E., Spear, J., and Kamauff, J. 2002. "Supply Chain Competency: Learning as a Key Component," Supply Chain Management: An International Journal (7:2), pp. 41-55.

Thompson, J. D. 1967. Organizations in Action, New York: McGraw-Hill.

Webb, A. 1991. "Coordination: A Problem in Public Sector Management," Policy and Politics (19:4), pp. 229-241.

Wigand, R. T., and Benjamin, R. I. 1995. "Electronic Commerce: Effects on Electronic Markets," Journal of Computer-Mediated Communication (1:3) (http://jcmc.indiana.edu/vol1/ issue3/wigand.html)

Zeng, A. Z., and Pathak, B. K. 2003. "Achieving Information Integration in Supply Chain Management through B2B E-Hubs: Concepts and Analyses," Industrial Management and Data Systems (103:9), pp. 657-665.

\section{About the Authors}

Deborah Bunker is a senior lecturer at the School of Information Systems, Technology \& Management at the University of New South Wales. She holds a Ph.D. in Information Systems Management. Her research interests are in IS philosophy, IS management, IS adoption and diffusion, and e-Commerce/e-Business. She has published widely in these areas. Deborah is a founding member and the Vice-Chair of IFIP TC 8 WG 8.6 on the adoption and diffusion of IT. She can be reached at d.bunker@unsw.edu.au.

Karlheinz Kautz is a professor in Systems Development and Software Engineering at the Department for Informatics at Copenhagen Business School. He holds a Ph.D. in systems development. His research interests are in the diffusion and adoption of information technology innovations, evolutionary systems development, and system development methodologies for advanced application areas, the organizational impact of IT, knowledge management, and software quality and process improvement. He has widely published in these areas. Karl is a founding member and is past Chairman of the IFIP TC 8 WG 8.6 on the adoption and diffusion of IT. He can be reached at Karl.Kautz@cbs.dk.

Clayton Pyne has been a student for the degree of Business Information Technology (Honours) at the University of New South Wales and has been a researcher for the project, which builds the basis for the research described here. 